\title{
Acceptability of Human Papillomavirus Self-Sampling Among a National Sample of Women in the United States
}

\author{
Erin Bishop, ${ }^{1}$ Mira L. Katz, ${ }^{2,3}$ and Paul L. Reiter ${ }^{2,3, *}$
}

\begin{abstract}
As human papillomavirus (HPV) self-sampling continues to emerge as a potential cervical cancer screening strategy in the United States, it is necessary to examine women's acceptability of this screening approach. Furthermore, since several HPV self-sampling devices exist, it is important to determine if women's preferences differ by device type. We conducted an online survey in Fall 2017 with a national sample of women $(n=605)$ ages 21-65 years (the recommended age range for cervical cancer screening). Multivariable linear regression identified correlates of women's willingness to use an HPV self-sample at home. We used repeated measures analysis of variance to determine if preferences differed across four self-sampling devices: Evalyn ${ }^{\circledR}$ Brush (Device A), HerSwab ${ }^{\circledR}$ (Device B), Catch-All ${ }^{\circledR}$ Swab (Device C), and Qvintip $^{\circledR}$ (Device D). Most women were willing to use an HPV self-sample at home (mean =4.03 [possible range: $1-5]$, standard deviation $=1.09,72.7 \%$ indicated "probably willing" or "definitely willing"). The most common concerns about self-sampling were related to test accuracy (53.1\%) and obtaining the sample incorrectly (51.1\%). Women were more willing to use an HPV self-sample at home if they reported greater perceived severity of cervical cancer $(\beta=0.16)$, reported an annual income less than $\$ 50,000(\beta=0.13)$, or were a former smoker $(\beta=0.11)$. Women were more willing to use Device A (mean $=3.72,67.6 \%$ indicated "agree" or "strongly agree"), Device $C$ (mean $=3.86$, 73.9\% indicated "agree" or "strongly agree"), and Device D (mean $=3.81,72.1 \%$ indicated "agree" or "strongly agree") than Device B (mean $=3.36,49.4 \%$ indicated "agree" or "strongly agree"; all $p<0.05$ ). Acceptability of HPV self-sampling as a cervical cancer screening strategy is generally high among women. Future efforts should consider the potential impact that device type may have on women's use of an HPV self-sample at home.
\end{abstract}

Keywords: cervical cancer; HPV; prevention; screening; women's health

\section{Introduction}

Persistent infection with high-risk types of human papillomavirus (HPV) cause nearly all cases of cervical cancer, ${ }^{1}$ and nearly $30 \%$ of adult women in the United States are infected with at least one high-risk type. ${ }^{2}$ Current guidelines recommend that women ages 21-65 years should be screened for cervical cancer. ${ }^{3}$ Women ages 21-29 years should receive cytology (i.e., a Pap test) every 3 years, and women ages 30-65 years should receive a combination of cytology and a clinic-based HPV test every 5 years, a clinic-based HPV test alone every 5 years, or cytology alone every 3 years. ${ }^{3}$ Despite recommendations, nearly $20 \%$ of U.S. women are not within these screening guidelines. ${ }^{4}$ Unscreened and underscreened women are at increased risk for cervical cancer since more than half of new cases of cervical cancer occur among such women. ${ }^{5}$

HPV self-sampling is a strategy that may help increase cervical cancer screening. HPV self-sampling allows women to use a mailed device to obtain a cervicovaginal sample at home. The sensitivity and specificity of self-collected samples are only slightly lower than provider-collected samples. ${ }^{6}$ HPV self-sampling may help women overcome some of the common barriers

\footnotetext{
${ }^{1}$ Medical Student Research Program, College of Medicine, The Ohio State University, Columbus, Ohio.

${ }^{2}$ Division of Health Behavior and Health Promotion, College of Public Health, The Ohio State University, Columbus, Ohio.

${ }^{3}$ Comprehensive Cancer Center, The Ohio State University, Columbus, Ohio.
}

*Address correspondence to: Paul L. Reiter, PhD, Division of Health Behavior and Health Promotion, College of Public Health, The Ohio State University, 1841 Neil Avenue, Room 359B, Columbus, OH 43210, E-mail: reiter.36@osu.edu

(C) Erin Bishop et al. 2019; Published by Mary Ann Liebert, Inc. This Open Access article is distributed under the terms of the Creative Commons License (http://creativecommons.org/licenses/by/4.0), which permits unrestricted use, distribution, and reproduction in any medium, provided the original work is properly cited. 
to clinic-based cervical cancer screening reported by women (e.g., lack of transportation, embarrassment, inconvenient clinic hours, etc. ${ }^{7,8}$ ). International studies have shown that up to about $40 \%$ of unscreened and underscreened women will use an HPV self-sample at home. ${ }^{9,10}$ Many of these studies also showed that HPV self-sampling produces larger increases in cervical cancer screening compared with other approaches (e.g., mailed reminders about cervical cancer screening). ${ }^{9,10}$ Several countries have therefore begun integrating self-sampling into their national cervical cancer screening programs. ${ }^{11,12}$

In the United States, studies have begun examining women's acceptability of HPV self-sampling. Past studies have found that most U.S. women are willing to use an HPV self-sample at home, but many of these studies were limited by small sample sizes, a limited geographic area, or the collection of only qualitative data. ${ }^{13-19}$ The type of HPV self-sampling device may play an important role in women's acceptability of this screening strategy. Several devices exist and differ greatly in appearance and functionality, with most acting as a brush, swab, or lavage. Recent research suggests that women prefer devices that are smaller in size, function as brushes or swabs (compared with lavages), and have a colorful appearance. $^{16,17,20}$ Given that women tend to prefer brushes and swabs, it becomes important to determine if their preferences differ across the various brushes and swabs that are currently available and if these preferences vary by demographic characteristics.

The current study examined the acceptability of HPV self-sampling as a cervical cancer screening strategy among a national sample of women. In doing so, we identified correlates of acceptability of self-sampling, determined how women's preferences vary across several self-sampling devices (i.e., brushes and swabs), and determined if these preferences differ by demographic characteristics. Results from this study can help guide the development of future cervical cancer screening programs in the United States that include HPV self-sampling.

\section{Materials and Methods}

Study design

We conducted a cross-sectional study with individuals who were female, ages 21 years or older, and lived in the United States. All women were existing members of an online survey panel, the SSRS Probability Panel. This panel is a voluntary online research panel that has been constructed through dual-frame random digit dial sampling. The panel is designed to be representative of the U.S. population. Panel members complete selfadministered online surveys on a regular basis in exchange for incentives (e.g., an electronic Amazon gift card). Panel members who were potentially eligible for our study received email invitations from SSRS to participate. Those who were interested then proceeded through weblink to confirm study eligibility. Panel members who were confirmed eligible then provided informed consent before completing their survey. The Institutional Review Board at The Ohio State University approved this study.

A total of 947 women completed our online survey in Fall 2017. We report data on 605 women from this study who were ages $21-65$ years (i.e., within the recommended age range for cervical cancer screening ${ }^{3}$ ). Women who were ages 66 years and older were not asked survey items about HPV self-sampling since cervical cancer screening is currently not recommended for these ages.

\section{Measures}

We developed survey items based on our previous HPV self-sampling research. ${ }^{16,18,19}$ Since many participants were likely unaware of HPV self-sampling before our survey, we presented women with general information about HPV self-sampling before asking any items about this topic.

HPV self-sampling. Our primary outcome was women's willingness to use an HPV self-sample at home. Willingness was assessed on a 5-point Likert scale with options, including "definitely not willing," "probably not willing," "not sure," "probably willing," and "definitely willing" (coded 1-5). The survey then asked women what concerns they would have about using an HPV self-sample at home. Women could indicate multiple responses from a list of potential concerns. We treated each concern as a dichotomous variable (indicated or not indicated).

The survey then included items about four specific HPV self-sampling devices (Fig. 1): (1) Evalyn ${ }^{\circledR}$ Brush (Rovers Medical Devices B.V., Oss, Netherlands), (2) HerSwab ${ }^{\circledR}$ (Eve Medical, Inc., Toronto, Canada), (3) Catch-All ${ }^{\circledR}$ Swab (Epicentre, Madison, WI), and (4) Qvintip ${ }^{\circledR}$ (Aprovix $A B$, Uppsala, Sweden). We included these devices because we wanted to compare several currently available brushes and swabs, as women tend to report greater willingness to use brushes and swabs compared with lavages. ${ }^{16,17,20}$ For the remainder of this report, we refer to the Evalyn Brush as Device A, HerSwab as Device B, Catch-All Swab as Device C, and Qvintip as Device D.

Device $\mathrm{A}$ is a brush that women insert into the vagina, push the plunger end to extend the brush, and 


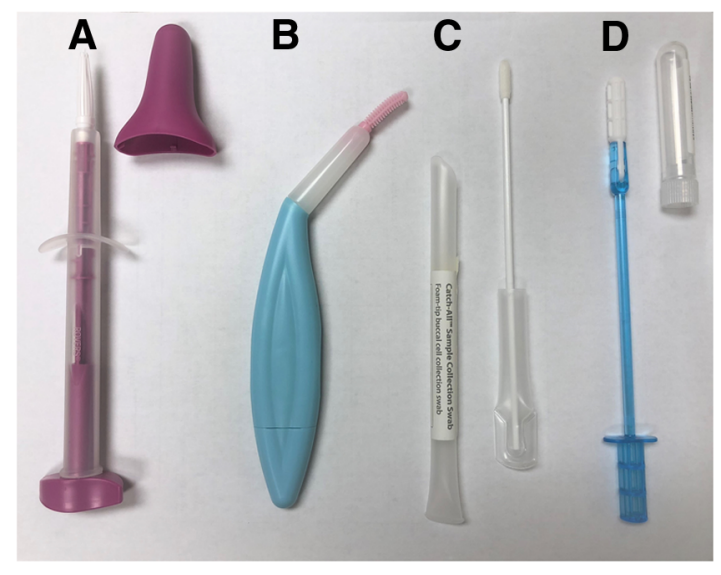

FIG. 1. HPV self-sampling devices shown to survey participants. Devices included the Evalyn ${ }^{\circledR}$ Brush (A), HerSwab ${ }^{\circledR}$ (B), Catch-All ${ }^{\circledR}$ Swab (C), and Qvintip ${ }^{\circledR}$ (D). HPV, human papillomavirus.

then rotate the plunger five times to collect the sample. For Device B, women insert the swab end of the device into the vagina until they reach the device's elbow. Women then turn the handle end until it stops, which extends the swab and collects the sample. For Device $\mathrm{C}$, women remove the swab from the plastic tube and obtain the sample by inserting the swab into the vagina and rotating it while slowly counting to 10 . For Device $\mathrm{D}$, women insert the white tip into the vagina and rotate the blue wand a few times to get the sample. Women then remove the device and break off the white tip into the plastic tube.

For each device separately, the survey presented participants with a picture of the device and a brief description of how the device works. The survey then included the same series of questions about each device that examined women's willingness to use each device, as well as their beliefs about device appearance and usability. Each item was assessed using a 5-point Likert scale with response options of "strongly disagree," "disagree," "not sure," "agree," and "strongly agree" (coded 1-5). The order in which participants viewed the devices was random, as was the ordering of the questions asked about each device.

Demographic and health-related characteristics. The survey assessed a wide range of demographic and health-related characteristics (Table 1). Sexual minority women were those who self-identified as lesbian, gay, bisexual, or other. Health-related characteristics included women's self-reported history of recent cervical cancer screening (i.e., Pap test in the last 3 years or clinic-based HPV test in the last 5 years), history of abnormal Pap tests, and history of HPV infection. We also examined women's perceived likelihood of getting cervical cancer (no chance, low chance, moderate chance, or high chance; coded 1-4) and perceived severity of cervical cancer (not at all, a little, moderately, or very; coded 1-4). Participants provided information on their height and weight, which we used to calculate body mass index (BMI) and then classify each woman as underweight or normal weight $(\mathrm{BMI}<24.9)$, overweight (BMI 25.0-29.9), or obese (BMI $\geq 30.0$ ).

\section{Data analyses}

We used descriptive statistics to examine women's general willingness to use an HPV self-sample at home and concerns about HPV self-sampling. We used linear regression to identify correlates of women's general willingness to use an HPV self-sample at home. We constructed a multivariable model containing all variables that were associated with willingness in bivariate analyses $(p<0.05)$. We report standardized regression coefficients $(\beta)$ from linear regression models.

To make comparisons across the four HPV selfsampling devices, we used repeated measures analysis of variance. We made post hoc pairwise comparisons of mean and used the Bonferroni adjustment to account for multiple comparisons. We then used general linear models to determine if women's willingness to use the four self-sampling devices differed by demographic characteristics. We considered differences to exist if an interaction term between a demographic characteristic and self-sampling device type had $p<0.05$. Data were analyzed using IBM SPSS version 25 (IBM Corp., Armonk, NY), and all statistical tests were two-tailed with a critical $\alpha$ of 0.05 .

\section{Results}

\section{Participant characteristics}

Most women were non-Hispanic white (76.9\%), married or living with a partner (67.9\%), employed (68.4\%), had at least a college degree (56.4\%), and reported an annual income of $\$ 50,000$ or more (59.5\%; Table 1$)$. The age distribution of women included $34.2 \%$ who were ages 21-40 years, $31.2 \%$ who were ages $41-55$ years, and $34.5 \%$ who were ages 56-65 years. Most women were never smokers $(60.0 \%)$, had a check-up with a health care provider in the last year (73.6\%), and had private health insurance $(74.5 \%)$. The majority of women were classified as obese (41.5\%) or overweight (26.6\%). 
Table 1. Demographic and Health-Related Characteristics of a National Sample of Women in the United States $(n=605)$

\begin{tabular}{|c|c|}
\hline Demographic characteristics & $n(\%)$ \\
\hline \multicolumn{2}{|l|}{ Age (years) } \\
\hline $21-40$ & $207(34.2)$ \\
\hline $41-55$ & 189 (31.2) \\
\hline $56-65$ & $209(34.5)$ \\
\hline \multicolumn{2}{|l|}{ Race/ethnicity } \\
\hline Non-Hispanic white & 465 (76.9) \\
\hline Non-Hispanic black & $55(9.1)$ \\
\hline Non-Hispanic other & $41(6.8)$ \\
\hline Hispanic & $44(7.3)$ \\
\hline \multicolumn{2}{|l|}{ Marital status } \\
\hline Married or living with a partner & $411(67.9)$ \\
\hline Other & $194(32.1)$ \\
\hline \multicolumn{2}{|l|}{ Education } \\
\hline College degree or more & $341(56.4)$ \\
\hline Less than a college degree & $264(43.6)$ \\
\hline \multicolumn{2}{|l|}{ Employment status } \\
\hline Currently employed & $414(68.4)$ \\
\hline Not currently employed & $191(31.6)$ \\
\hline \multicolumn{2}{|l|}{ Income } \\
\hline Less than $\$ 50,000$ & $207(34.2)$ \\
\hline$\$ 50,000$ or more & $360(59.5)$ \\
\hline Not reported & $38(6.3)$ \\
\hline \multicolumn{2}{|l|}{ Geographic region of residence } \\
\hline Northeast & $129(21.3)$ \\
\hline North Central & $154(25.5)$ \\
\hline South & $189(31.2)$ \\
\hline West & $133(22.0)$ \\
\hline \multicolumn{2}{|l|}{ Urbanicity of residence } \\
\hline Urban/metropolitan & $507(83.8)$ \\
\hline Rural/nonmetropolitan & $98(16.2)$ \\
\hline \multicolumn{2}{|l|}{ Sexual orientation } \\
\hline Sexual minority & $59(9.8)$ \\
\hline Heterosexual & $546(90.2)$ \\
\hline Health-related characteristics & $n(\%)$ \\
\hline \multicolumn{2}{|l|}{ BMI } \\
\hline Underweight or normal weight & $193(31.9)$ \\
\hline Overweight & $161(26.6)$ \\
\hline Obese & $251(41.5)$ \\
\hline \multicolumn{2}{|l|}{ Smoking status } \\
\hline Never smoker & $363(60.0)$ \\
\hline Former smoker & $160(26.4)$ \\
\hline Current smoker & $82(13.6)$ \\
\hline \multicolumn{2}{|l|}{$\begin{array}{l}\text { Check-up with health } \\
\text { care provider in the last year }\end{array}$} \\
\hline Yes & 445 (73.6) \\
\hline No & $160(26.4)$ \\
\hline \multicolumn{2}{|l|}{ Health insurance status } \\
\hline No health insurance & $41(6.8)$ \\
\hline Public health insurance & $113(18.7)$ \\
\hline Private health insurance & $451(74.5)$ \\
\hline \multicolumn{2}{|l|}{$\begin{array}{l}\text { Within recommended cervical } \\
\text { cancer screening guidelines }{ }^{\mathrm{a}}\end{array}$} \\
\hline Yes & $499(82.5)$ \\
\hline No & $106(17.5)$ \\
\hline \multicolumn{2}{|l|}{ History of abnormal Pap test results } \\
\hline Yes & $221(36.5)$ \\
\hline No & $384(63.5)$ \\
\hline
\end{tabular}

Table 1. (Continued)

\begin{tabular}{lr}
\hline Health-related characteristics & $\boldsymbol{n}(\%)$ \\
\hline History of HPV infection & $75(12.4)$ \\
Yes & $530(87.6)$ \\
$\quad$ No & $2.03(0.67)$ \\
Perceived likelihood of getting cervical cancer & b,c \\
Perceived severity of cervical cancer,d $^{c, d}$ & $3.47(0.79)$
\end{tabular}

Note: Percentages may not total $100 \%$ due to rounding.

a Based on guidelines that were in place at the time of our study (i.e. Pap test in the last 3 years or clinic-based HPV test in the last 5 years). ${ }^{21}$

${ }^{\mathrm{b}} 4$-point Likert scale with responses from $1=$ "No chance" to $4=$ "High chance."

'Mean and SD are reported.

d4-point Likert scale with responses from $1=$ "Not at all" to $4=$ "Very." $B M I$, body mass index; HPV, human papillomavirus; SD, standard deviation.

Most women reported being within the cervical cancer screening guidelines that were in place at the time of our study ${ }^{21}(82.5 \%)$. Over $35 \%$ of women indicated a history of abnormal Pap test results and $12.4 \%$ reported a history of HPV infection (12.4\%).

\section{Acceptability of and concerns about HPV}

self-sampling

Women, on average, reported high willingness to use an HPV self-sample at home (mean $=4.03$, standard deviation $=1.09$ ). This included $72.7 \%$ of women reporting that they were "probably willing" or "definitely willing" to use an HPV self-sample at home. The most common concerns about HPV self-sampling reported by women included concerns about test accuracy (53.1\%), concerns about obtaining the sample incorrectly $(51.1 \%)$, preferring to see a health care provider to get screened for cervical cancer rather than using a self-sample (25.3\%), not wanting to return the self-sample through the mail (10.6\%), and concerns about pain while using a self-sample (9.8\%). All other concerns were reported by less than $5 \%$ of women. Nearly $20 \%$ of women $(19.2 \%)$ indicated that they did not have any concerns about using a self-sample.

In bivariate analyses, women were more willing to use an HPV self-sample at home if they had reported an annual income of less than $\$ 50,000(\beta=0.09$, $p=0.025)$, were a former smoker $(\beta=0.12, p=0.004)$, reported greater perceived likelihood of getting cervical cancer $(\beta=0.11, p=0.008)$, or reported greater perceived severity of cervical cancer $(\beta=0.18, p<0.001$; Table 2). Women were less willing to use an HPV self-sample at home if they had at least a college degree $(\beta=-0.09, p=0.021)$ or had public health insurance $(\beta=-0.14, p=0.049)$. 
Table 2. Correlates of Women's Willingness to Use an Human Papillomavirus Self-Sample at Home $(n=605)$

\begin{tabular}{|c|c|c|c|}
\hline Demographic characteristics & Mean (SD) & Bivariate $\beta$ & Multivariable $\beta$ \\
\hline \multicolumn{4}{|l|}{ Age (years) } \\
\hline $21-40$ & $3.99(1.03)$ & Ref. & - \\
\hline $41-55$ & $4.06(1.20)$ & 0.03 & - \\
\hline $56-65$ & $4.04(1.05)$ & 0.02 & - \\
\hline \multicolumn{4}{|l|}{ Race/ethnicity } \\
\hline Non-Hispanic white & $4.04(1.07)$ & 0.10 & - \\
\hline Non-Hispanic black & $4.11(0.99)$ & 0.09 & - \\
\hline Non-Hispanic other & $3.78(1.19)$ & Ref. & - \\
\hline Hispanic & $4.07(1.35)$ & 0.07 & - \\
\hline \multicolumn{4}{|l|}{ Marital status } \\
\hline Married or living with a partner & $4.01(1.09)$ & -0.03 & - \\
\hline Other & $4.07(1.10)$ & Ref. & - \\
\hline \multicolumn{4}{|l|}{ Education } \\
\hline College degree or more & $3.94(1.09)$ & $-0.09 *$ & -0.06 \\
\hline Less than a college degree & $4.15(1.08)$ & Ref. & Ref. \\
\hline \multicolumn{4}{|l|}{ Employment status } \\
\hline Currently employed & $4.01(1.09)$ & -0.03 & - \\
\hline Not currently employed & $4.08(1.10)$ & Ref. & - \\
\hline \multicolumn{4}{|l|}{ Income } \\
\hline Less than $\$ 50,000$ & $4.17(0.99)$ & $0.09^{*}$ & $0.13^{* *}$ \\
\hline$\$ 50,000$ or more & $3.96(1.13)$ & Ref. & Ref. \\
\hline Not reported & $4.00(1.23)$ & 0.01 & 0.01 \\
\hline \multicolumn{4}{|l|}{ Geographic region of residence } \\
\hline Northeast & $3.96(1.06)$ & Ref. & - \\
\hline North Central & $4.03(1.06)$ & 0.03 & - \\
\hline South & $4.12(1.05)$ & 0.07 & - \\
\hline West & $3.97(1.22)$ & 0.00 & - \\
\hline \multicolumn{4}{|l|}{ Urbanicity of residence } \\
\hline Urban/metropolitan & $4.04(1.10)$ & 0.01 & - \\
\hline Rural/nonmetropolitan & $4.00(1.07)$ & Ref. & - \\
\hline \multicolumn{4}{|l|}{ Sexual orientation } \\
\hline Sexual minority & $3.85(1.14)$ & -0.06 & - \\
\hline Heterosexual & $4.05(1.09)$ & Ref. & - \\
\hline Health-related characteristics & Mean (SD) & Bivariate $\beta$ & Multivariable $\beta$ \\
\hline \multicolumn{4}{|l|}{ BMI } \\
\hline Underweight or normal weight & $4.01(1.13)$ & -0.03 & - \\
\hline Overweight & $3.98(1.10)$ & -0.04 & - \\
\hline Obese & $4.08(1.06)$ & Ref. & - \\
\hline \multicolumn{4}{|l|}{ Smoking status } \\
\hline Never smoker & $3.93(1.11)$ & Ref. & Ref. \\
\hline Former smoker & $4.23(0.99)$ & $0.12^{* *}$ & $0.11^{* *}$ \\
\hline Current smoker & $4.11(1.18)$ & 0.06 & 0.04 \\
\hline \multicolumn{4}{|l|}{ Check-up with health care provider in the last year } \\
\hline Yes & $4.03(1.12)$ & -0.01 & - \\
\hline No & $4.04(1.01)$ & Ref. & - \\
\hline \multicolumn{4}{|l|}{ Health insurance status } \\
\hline No health insurance & $4.29(1.08)$ & Ref. & Ref. \\
\hline Public health insurance & $3.90(1.25)$ & $-0.14^{*}$ & $-0.14^{*}$ \\
\hline Private health insurance & $4.04(1.05)$ & -0.10 & -0.02 \\
\hline \multicolumn{4}{|c|}{ Within recommended cervical cancer screening guidelines $\mathrm{s}^{\mathrm{a}}$} \\
\hline Yes & $4.04(1.07)$ & 0.01 & - \\
\hline No & $4.00(1.19)$ & Ref. & - \\
\hline \multicolumn{4}{|l|}{ History of abnormal Pap test results } \\
\hline Yes & $4.11(1.03)$ & 0.06 & - \\
\hline No & $3.98(1.12)$ & Ref. & - \\
\hline \multicolumn{4}{|l|}{ History of HPV infection } \\
\hline Yes & $4.20(1.05)$ & 0.06 & - \\
\hline No & $4.01(1.10)$ & Ref. & - \\
\hline Perceived likelihood of getting cervical cancer ${ }^{b}$ & - & $0.11^{* *}$ & 0.07 \\
\hline Perceived severity of cervical cancer ${ }^{c}$ & - & $0.18^{* * *}$ & $0.16^{* * *}$ \\
\hline
\end{tabular}

Note: Willingness was measured using a 5 -point scale ranging from $1=$ "definitely not willing" to $5=$ "definitely willing." $\beta$ represents standardized regression coefficients. Dashes $(-)$ indicate that variable was not included in the multivariable model.

${ }^{a}$ Based on guidelines that were in place at the time of our study (i.e., Pap test in the last 3 years or clinic-based HPV test in the last 5 years). ${ }^{21}$

b-point Likert scale with responses from $1=$ "No chance" to $4=$ "High chance."

c4-point Likert scale with responses from $1=$ "Not at all" to $4=$ "Very."

${ }^{*} p<0.05,{ }^{* *} p<0.01,{ }^{* * *} p<0.001$. 
Table 3. Women's Preferences Across Human Papillomavirus Self-Sampling Devices

\begin{tabular}{|c|c|c|c|c|c|}
\hline & Device A & Device B & Device C & Device D & Comparisons* \\
\hline I would be willing to use this device at home by myself & $3.72(1.05)$ & $3.36(1.09)$ & $3.86(1.01)$ & $3.81(1.02)$ & $1,2,4,5$ \\
\hline I like how this device looks & $3.40(0.99)$ & $2.75(1.02)$ & $3.45(0.99)$ & $3.54(0.96)$ & $1,3,4,5$ \\
\hline This device would be easy to use & $3.65(0.95)$ & $3.22(0.97)$ & $3.82(0.91)$ & $3.80(0.94)$ & $1,2,3,4,5$ \\
\hline I would be worried that it would hurt to use this device & $2.68(1.14)$ & $2.83(1.16)$ & $2.28(1.04)$ & $2.38(1.07)$ & $1,2,3,4,5,6$ \\
\hline I would be embarrassed to use this device & $1.83(0.93)$ & $1.90(0.91)$ & $1.75(0.82)$ & $1.74(0.84)$ & $2,3,4,5$ \\
\hline
\end{tabular}

Note: Table reports means and SDs. All items were rated on a 5-point Likert scale with responses ranging from $1=$ "Strongly disagree" to $5=$ "Strongly agree."

${ }^{*}$ Column indicates comparisons in mean with $p<0.05$ following Bonferroni adjustment. Results were obtained through repeated measures analysis of variance. The numbers represent the following comparisons: $1=$ Device A different than Device $B, 2=$ Device $A$ different than Device $C$, 3 = Device A different than Device D, 4 = Device B different than Device C, $5=$ Device B different than Device $D$, and $6=$ Device $C$ different than Device D.

In multivariable analyses, women were more willing to use an HPV self-sample at home if they reported an annual income of less than $\$ 50,000 \quad(\beta=0.13$, $p=0.005)$, were a former smoker $(\beta=0.11, p=0.007)$, or reported a greater perceived severity of cervical can$\operatorname{cer}(\beta=0.16, p<0.001)$. Women were less willing to use an HPV self-sample at home if they had public health insurance $(\beta=-0.14, p=0.039)$.

\section{Comparisons of HPV self-sampling devices}

Overall, women tended to rate Devices A, C, and D more positively than Device B (Table 3 ). Women were more willing to use Device A (mean $=3.72,67.6 \%$ indicated "agree" or "strongly agree"), Device C (mean $=3.86$, $73.9 \%$ indicated "agree" or "strongly agree"), and Device
D $($ mean $=3.81,72.1 \%$ indicated "agree" or "strongly agree") compared with Device B (mean $=3.36,49.4 \%$ indicated "agree" or "strongly agree"; all $p<0.05)$. Devices A, C, and D were rated more positively than Device B in terms of how the device looks and women believing that the device would be easy to use (all $p<0.05$ ). In contrast, women indicated the greatest level of worry that it would hurt to use Device B (mean $=2.83$ ) compared with other devices (mean ranged from 2.28 to 2.68; all $p<0.05$ ). Women tended to report low levels of potential embarrassment about using each device (all means $<2.00$ ), although differences across devices did exist.

Differences in women's willingness to use the four devices varied by sexual orientation ( $p=0.01$ for interaction term; Fig. 2). Sexual minority women reported higher

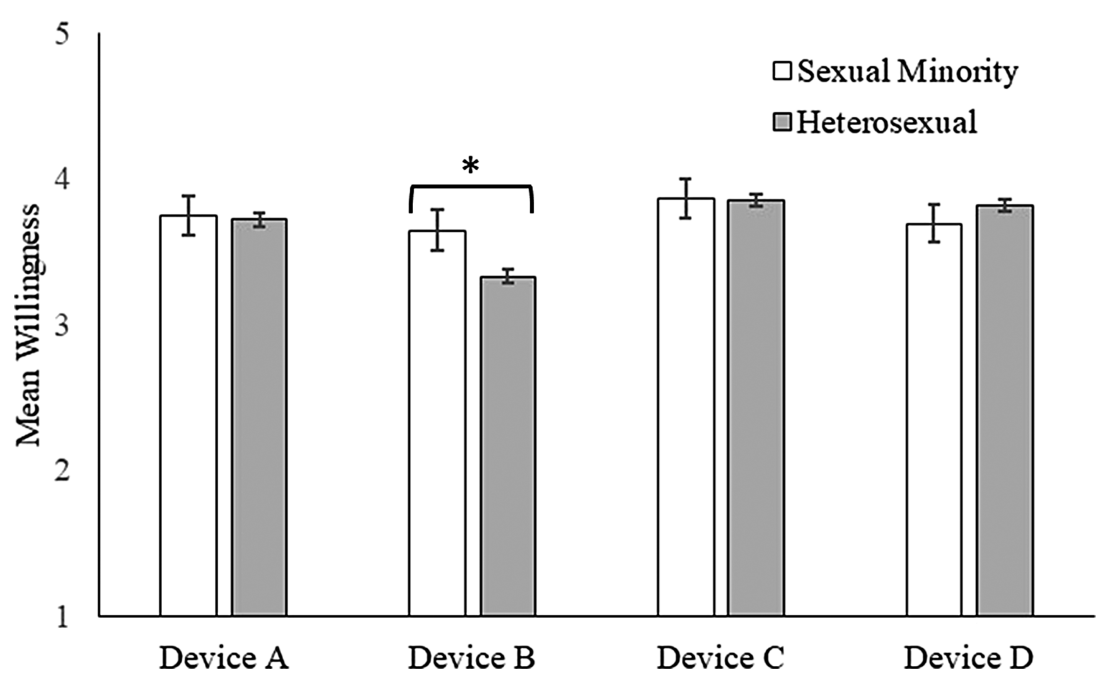

FIG. 2. Women's willingness to use HPV self-sampling devices at home by sexual orientation. Response scale ranged from $1=$ "strongly disagree" to $5=$ "strongly agree." Bars indicate standard errors. "**" indicates a comparison with $p<0.05$. 
willingness than heterosexual women to use Device $\mathrm{B}$ $($ mean $=3.64$ vs. mean $=3.33$ ), with willingness to use the other devices being similar. Differences in willingness to use the four devices did not vary by other demographic characteristics ( $p>0.05$ for all other interaction terms).

\section{Discussion}

Most women in the current study were accepting HPV self-sampling as a cervical cancer screening strategy, which supports past studies conducted among women in the United States. ${ }^{13-19}$ Participants tended to report few concerns about self-sampling, and nearly $20 \%$ reported no concerns. Of the concerns reported, the most common involved test accuracy and the ability to obtain a sample correctly. These findings are similar to those from recent U.S. studies ${ }^{13,18,19}$ and identify concerns that will likely need to be addressed to maximize the success of HPV self-sampling programs. For example, to address women's concerns about obtaining a self-sample correctly, programs should stress that most women who have used a self-sample reported that it was easy to use and were able to successfully obtain an adequate sample. ${ }^{22-24}$

Several variables were correlated with women's willingness to use an HPV self-sample at home. Women with lower incomes were more willing to use a selfsample, which is encouraging since women with lower socioeconomic status are less likely to have received a recent clinic-based cervical cancer screening test. ${ }^{4}$ Women in our study with lower incomes may have viewed HPV self-sampling as a screening strategy that reduces some barriers associated with clinic-based screening (e.g., transportation, cost). ${ }^{7,8}$ Former smokers were also more willing to use an HPV self-sample at home. Smoking is a risk factor for cervical cancer, ${ }^{25}$ and former smokers may have perceived themselves to be at greater risk for cervical cancer and therefore more willing to use a self-sample for screening. Although former smokers were more willing to use an HPV self-sample, there was no difference in willingness found among current smokers. This may be attributable to former smokers tending to utilize preventive services much more frequently than current smokers. ${ }^{26}$ Lastly, women who reported a greater perceived severity of cervical cancer were more willing to use a self-sample at home. Perceived severity is a construct in several theories of health behavior ${ }^{27,28}$ and represents a modifiable belief that can be targeted by future efforts to increase women's acceptability and subsequent use of an HPV self-sample.
Device type may play an important role in women's acceptability of HPV self-sampling. Women were more willing to use those devices that more closely resemble a basic swab (Devices C and D). This may be due in part to the appearance and perceived usability of these devices, as women indicated these devices were the most visually appealing, would be the easiest to use, and would be the least likely to cause pain or embarrassment. Contrary to a recent study, ${ }^{16}$ the devices in our study that were more colorful (Devices A and B) or contained wings (Device A) or elbows (Device B) that help standardize insertion depth were not rated more positively by women. This may be because women in our study compared these devices with only other swabs and brushes, whereas women in the past study compared them with devices that function and look very differently (e.g., a lavage). Future efforts are needed to determine the potential impact that device type may have on women's actual use of an HPV self-sample mailed to their home.

Device preference did not differ greatly across demographic characteristics. However, we did find differences by sexual orientation, with sexual minority women being more willing to use Device B than heterosexual women. A recent study found that most sexual minority women are accepting of HPV self-sampling as a screening strategy, ${ }^{19}$ but our study is the first that we are aware of to examine their device preferences. Our findings not only show the importance of conducting formative research on device preferences across various populations but also can help inform future screening programs for sexual minority women, many of whom are infected with a high-risk HPV type ${ }^{29}$ but have not been recently screened for cervical cancer. ${ }^{30}$

Study strengths include a large sample size of women from across the United States, quantitative data on acceptability of HPV self-sampling, and data on women's preferences across several self-sampling devices. Limitations include participants only having the ability to view information and pictures about HPV self-sampling and the various devices and not have the opportunity to actually use the devices. Although our study provides useful information on women's attitudes and preferences for self-sampling, it is possible that their reported willingness may not translate into actual behavior. There is also the possibility that women may express different opinions when comparing multiple devices than when viewing a device in isolation, although we did randomize the order in which participants viewed the devices. Most participants were non-Hispanic white, lived in urban areas, 
and reported being within cervical cancer screening guidelines, although it is worth noting that these variables were not associated with women's willingness to use an HPV self-sample at home. Lastly, HPV self-sampling is not an approved or recommended cervical cancer screening strategy in the United States, and women's attitudes and preferences for self-sampling may change if approval and recommendations occur in the future.

\section{Conclusions}

Acceptability of HPV self-sampling as a cervical cancer screening strategy is generally high among women in the United States, regardless of demographic characteristics. Women's most common concerns involved test accuracy and the ability to obtain a sample correctly. Device type may play a key part in women's acceptability of self-sampling, as women tend to prefer simpler devices that resemble a basic swab. As HPV selfsampling continues to emerge as a screening strategy in the United States, our findings can help guide the development of cervical cancer screening programs that include HPV self-sampling.

\section{Acknowledgments}

This study was supported by a research grant from Pelotonia at The Ohio State University Comprehensive Cancer Center and by the OSU College of Medicine Roessler research scholarship.

\section{Author Disclosure Statement}

No competing financial interests exist.

\section{References}

1. International Agency for Research on Cancer. Monographs on the Evaluation of Carcinogenic Risks to Humans, Volume 90: Human Papillomaviruses. World Health Organization, International Agency for Research on Cancer: Lyon, France, 2007.

2. Hariri S, Unger ER, Sternberg M, et al. Prevalence of genital human papillomavirus among females in the United States, the national health and nutrition examination survey, 2003-2006. J Infect Dis. 2011;204:566-573.

3. US Preventive Services Task Force, Curry SJ, Krist AH, et al. Screening for cervical cancer: US Preventive Services Task Force recommendation statement. JAMA. 2018;320:674-686.

4. White $A$, Thompson TD, White MC, et al. Cancer screening test use-United States, 2015. MMWR Morb Mortal Wkly Rep. 2017;66: 201-206.

5. Spence AR, Goggin P, Franco EL. Process of care failures in invasive cervical cancer: systematic review and meta-analysis. Prev Med. 2007;45: 93-106.

6. Arbyn M, Verdoodt F, Snijders PJ, et al. Accuracy of human papillomavirus testing on self-collected versus clinician-collected samples: a metaanalysis. Lancet Oncol. 2014;15:172-183.

7. Glasgow RE, Whitlock EP, Valanis BG, et al. Barriers to mammography and pap smear screening among women who recently had neither, one or both types of screening. Ann Behav Med. 2000;22: 223-228.
8. Studts CR, Tarasenko YN, Schoenberg NE. Barriers to cervical cancer screening among middle-aged and older rural Appalachian women. J Community Health. 2013;38:500-512.

9. Verdoodt $F$, Jentschke $M$, Hillemanns $P$, et al. Reaching women who do not participate in the regular cervical cancer screening programme by offering self-sampling kits: a systematic review and meta-analysis of randomised trials. Eur J Cancer. 2015;51: 2375-2385.

10. Racey CS, Withrow DR, Gesink D. Self-collected HPV testing improves participation in cervical cancer screening: a systematic review and meta-analysis. Can J Public Health. 2013;104:e159-e166.

11. Arbyn M, Castle PE. Offering self-sampling kits for HPV testing to reach women who do not attend in the regular cervical cance screening program. Cancer Epidemiol Biomarkers Prev. 2015;24: 769-772.

12. Smith M, Lew JB, Simms K, et al. Impact of HPV sample self-collection for underscreened women in the renewed cervical screening program. Med J Aust. 2016;204:1941e-7.

13. Madzima TR, Vahabi M, Lofters A. Emerging role of HPV self-sampling in cervical cancer screening for hard-to-reach women: focused literature review. Can Fam Physician. 2017;63:597-601.

14. Scarinci IC, Litton AG, Garces-Palacio IC, et al. Acceptability and usability of self-collected sampling for HPV testing among African-American women living in the Mississippi delta. Womens Health Issues. 2013;23: e123-e130.

15. Vanderpool RC, Jones MG, Stradtman LR, et al. Self-collecting a cervico-vaginal specimen for cervical cancer screening: an exploratory study of acceptability among medically underserved women in rural Appalachia. Gynecol Oncol. 2014;132(Suppl. 1):S21-S25.

16. Reiter PL, Richardson M, Zimmermann BJ, et al. Acceptability of human papillomavirus self-test devices among women from high-risk populations. J Womens Health, Issues Care. 2016;5.

17. Richman AR, Brewer NT, Liebman AK, et al. Optimising human papillomavirus self-testing for high risk women. Sex Transm Infect. 2011;87: 118-122.

18. Katz ML, Zimmermann BJ, Moore D, et al. Perspectives from health-care providers and women about completing human papillomavirus (HPV) self-testing at home. Women Health. 2017;57:1161-1177.

19. Reiter PL, McRee AL. Cervical cancer screening (pap testing) behaviours and acceptability of human papillomavirus self-testing among lesbian and bisexual women aged 21-26 years in the USA. J Fam Plann Reprod Health Care. 2015;41:259-264.

20. Szarewski A, Cadman L, Ashdown-Barr L, et al. Exploring the acceptability of two self-sampling devices for human papillomavirus testing in the cervical screening context: a qualitative study of Muslim women in London. J Med Screen. 2009;16:193-198.

21. Saslow D, Solomon D, Lawson HW, et al. American Cancer Society, American Society for Colposcopy and Cervical Pathology, and American Society for Clinical Pathology screening guidelines for the prevention and early detection of cervical cancer. CA Cancer J Clin. 2012; 62:147-172

22. Karjalainen $L$, Anttila $A$, Nieminen $P$, et al. Self-sampling in cervical cancer screening: comparison of a brush-based and a lavage-based cervicovaginal self-sampling device. BMC Cancer. 2016;16:221.

23. Bosgraaf RP, Verhoef VM, Massuger LF, et al. Comparative performance of novel self-sampling methods in detecting high-risk human papillomavirus in 30,130 women not attending cervical screening. Int J Cancer. 2015;136:646-655.

24. Enerly E, Bonde J, Schee K, et al. Self-sampling for human papillomavirus testing among non-attenders increases attendance to the Norwegian cervical cancer screening programme. PLoS One. 2016;11:e0151978.

25. U.S. Department of Health and Human Services. The Health Consequences of Smoking-50 Years of Progress. A Report from the Surgeon General. Department of Health and Human Services, Center for Disease Control and Prevention, National Center for Chronic Disease Prevention and Health Promotion: Atlanta, GA, 2014.

26. Vander Weg MW, Howren MB, Cai X. Use of routine clinical preventive services among daily smokers, non-daily smokers, former smokers, and never-smokers. Nicotine Tob Res. 2012;14 123-130. 
27. Rogers RW. Cognitive and physiological processes in fear appeals and attitude change: a revised theory of protection motivation. In: Cacioppo JT, Petty RE, eds. Social Psychophysiology: A Source Book. Guilford Press: New York; pp. 153-176; 1983.

28. Becker MH. The health belief model and personal health behavior. Health Educ Monogr. 1974;2:324-473.

29. Reiter PL, McRee AL. HPV infection among a population-based sample of sexual minority women from USA. Sex Transm Infect. 2017;93: 25-31.

30. Agenor M, Krieger N, Austin SB, et al. Sexual orientation disparities in papanicolaou test use among US women: the role of sexual and reproductive health services. Am J Public Health. 2014;104: e68-e73.
Cite this article as: Bishop E, Katz ML, Reiter PL (2019) Acceptability of human papillomavirus self-sampling among a national sample of women in the United States, BioResearch Open Access 8:1, 65-73, DOI: 10.1089/biores.2018.0040.

\section{Publish in BioResearch Open Access}

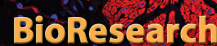

OPEN ACCESS

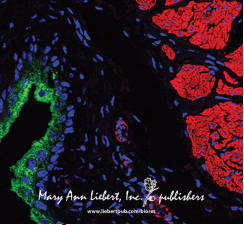

- Broad coverage of biomedical research

- Immediate, unrestricted online access

- Rigorous peer review

- Compliance with open access mandates

- Authors retain copyright

- Highly indexed

- Targeted email marketing

liebertpub.com/biores 